\title{
SOBRE AS CONTRIBUIÇÕES DO PENSAMENTO ORIENTAL NA TEORIA ÉTICA DE ARTHUR SCHOPENHAUER
}

Maria Gomes Fernandes ${ }^{1}$

\begin{abstract}
RESUMO: Esta comunicação tem como objetivo discutir o fundamento da ação moral na filosofia de Schopenhauer, destacando as possíveis contribuições ou influências recebidas mediante suas leituras do pensamento oriental, realizadas no período de formação da sua filosofia. Para tanto, será enfatizado alguns conceitos oriundos da sabedoria Védica, como véu de Màyā e a expressão Tat tvam asi, no intuito de depreender seus significados mais profundos e, assim, as possíveis relações que elas mantêm com os conceitos de representação e compaixão na teoria schopenhaueriana.
\end{abstract}

Palavras-chave: Schopenhauer. Compaixão. Pensamento oriental. Ética.

\section{EXPERIÊNCIAS OBTIDAS NESTE EVENTO}

Arthur Schopenhauer apresentou uma reflexão ética na qual o valor moral de uma ação fundamenta-se na experiência do sentimento da compaixão. Se, para a cultura Ocidental, essa ética alicerçada em ações compassivas que brotam espontaneamente de uma intuição imediata do mundo surge como uma novidade, no Oriente, ao contrário, trata-se de uma noção milenar que compõe a sabedoria de vida dessa tradição. Schopenhauer declarou, logo no primeiro prefácio de sua principal obra, O mundo como vontade e representação (1819) que, para que se tenha uma compreensão adequada da sua obra é fundamental que o leitor tenha familiaridade com a filosofia do "maravilhoso Kant", do "divino Platão" bem como da Antiga sabedoria indiana.

As expressões e terminologias da sabedoria oriental presentes em $\mathrm{O}$ mundo como vontade e representação como, por exemplo, o "Véu de Maia" e Tat tvam asi, são mencionadas inicialmente apenas para elucidar o seu pensamento único. Schopenhauer chega a afirmar, inclusive, que as máximas presentes nas Upanixades são "admiráveis concordâncias" com aquilo que a sua filosofia também expressa. Porém, quando Schopenhauer apresenta a sua primeira tese de que o mundo é representação sob a perspectiva do fenômeno kantiano e a ilusão de Māya (conceito que lhe chega por meio dos hindus) bem como se apropria da fórmula védica Tat tvam asi para se referir

\footnotetext{
${ }^{1}$ Ma. Pelo programa de Pós Graduação em Ética e Epistemologia da UFPI. Atualmente professora substituta do Departamento de Pedagogia da Universidade Federal do Piauí, Campus Helvídio Nunes na cidade de Picos-PI.
} 
ao sentimento da compaixão (que constitui o fundamento apresentado por Schopenhauer para a genuína ação moral), observa-se que essas noções ganham uma relevância teórica que parece ultrapassar uma análise comparativa entre os pensamentos, a saber, o schopenhaueriano e o oriental.

Schopenhauer apresentou uma ética com bases metafísicas, na qual somente no mundo fenomênico somos indivíduos particulares. Porém, como essência última de nosso ser, somos um e sem distinção. Em outras palavras, Schopenhauer descreve-nos que, por meio do conhecimento da essência do mundo, que ele chama de Vontade, os indivíduos podem se identificar uns com os outros, compartilhando as dores e as alegrias. Esse raciocínio descrito por Schopenhauer assemelha-se com o pensamento milenar oriental, pois, tanto nas considerações schopenhauerianas como na sabedoria hindu, quando ferimos alguém estamos, na verdade, ferindo a nós mesmos. Neste sentido, em que medida poderíamos considerar essa unidade metafísica presente em todos os seres - que na teoria ética de Schopenhauer é reconhecida em si mesma e imediatamente no outro pela experiência da ação compassiva - como semelhante à unidade presente em toda a Natureza apontada pela fórmula Tat tvam asi descrita pelos sábios da Índia? Essa aproximação seria apenas uma "feliz concordância" ou teríamos algum tipo de influência direta dessa tradição com o pensamento de Schopenhauer? A resposta apresentada a estes questionamentos constitui a parte fundamental desta discussão.

A constatação ${ }^{2}$ desse interesse pelos ensinamentos das escrituras orientais, mais propriamente dos sábios da Índia, comprova-se pelas leituras acerca daquele continente realizadas por Schopenhauer, que notadamente se iniciaram após a publicação de sua tese de doutorado, em 1813. Schopenhauer teria seguido a recomendação do orientalista Friedrich Majer, que lhe recomendara a leitura dos cinquenta Upanixades traduzidos para o latim por Anquetil-Duperron ${ }^{3}$.

\section{Os conceitos hindus: Māyāe Tat tvam asi}

$\mathrm{Na}$ filosofia vedantina, Màyä é descrita como uma deusa que tem o poder mágico de criação e ilusão das coisas deste mundo. Ela, Mãyā, também é conceituada como "a ilusão

\footnotetext{
2 Podemos encontrar exemplos citados por Schopenhauer de práticas de diferentes povos e épocas, em $O$ mundo..., mais precisamente, na página 493.

3 "Deve-se ao francês Anquetil-Duperron a edição de uma coletânea de textos sob o título Oupnekhat (uma deformação da palavra sânscrita 'Upanixades'). Nesta edição os textos estavam duplamente obscurecidos, pois se tratava de uma tradução latina de uma tradução anterior dos textos sânscritos para o idioma farsi, ou seja, o persa" (SAFRANSKI, 2012, p. 368). Conforme Safranski, esta, provavelmente, foi a tradução mais importante dos Upanixades, publicada em 1801.
} 


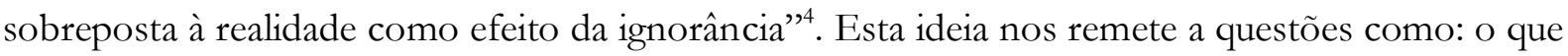
é real? Como o indivíduo, estando iludido, pode identificar o real a partir da aparência transitória de $M a \bar{y} a \vec{a}$. Existe uma unidade básica que fundamente a multiplicidade?

A tradição védica considera que somente o uno, eterno e imutável (Brahman) pode ser considerado real. Entretanto, Māyāa, segundo essa tradição, é uma deusa com poderes de criação e ao mesmo tempo de ilusão deste mundo; ela é a causa da matéria e dos indivíduos. A ilusão criada por Mãyà é a responsável pela ignorância dos indivíduos, que, por desconhecerem a verdade, enganam-se com a aparente realidade. Tais características se revelam por meio da transitoriedade da vida. Nesse eterno movimento resta aos indivíduos a condição de "escravos da ilusão" de uma falsa realidade do mundo, ou seja, vivem em um mundo de aparência. Essa mesma potência criadora de toda a existência do mundo é também a que com seu "véu" encobre tanto a percepção do indivíduo sobre o real como também engana o autor da ação egoísta, pois em tais ações acredita-se estar agindo em benefício próprio, no entanto, a verdade é outra. Podemos confirmar essa linha de pensamento na passagem abaixo:

Segundo as Upanishades, Māyā é ilusão, pura imaginação, fantasia, isto é, tudo é ilusão, Maia. Para muitos orientalistas, a divindade Mãya se apresenta de forma confusa e até contraditória, pois carrega consigo as características de criação e ao mesmo tempo ilusão. No hinduísmo o mutável é irreal e o imutável é o real, portanto o transitório é falso e apenas uma miragem fantasiosa. Partindo do caráter transitório do mundo Màyà se expressa como sua causa e efeito, por isso Mãyā é a causa do mundo, é a mãe do universo graças a seu poder de criar. Dessa forma todos os seres estão enraizados em sua criação, que muitas das vezes é comparável a uma teia de aranha, que captura os seres que nela se enredam e, ao mesmo tempo, também, os gera e os mantém em um eterno devir. A teia de Mãyā representa assim a incapacidade do homem de libertar-se dela Māyā. Os seres são enganados pelo poder de atração de Māyā e nessa impossibilidade de livrar-se dela caem numa ilusória realidade (uma irrealidade) que se mostra como um véu que encobre a visão de todos, por esse motivo muito se utiliza a expressão o véu de Màyà. (REDYSON, 2010, pp. 07-08)

Aqueles indivíduos que conseguirem retirar esse "véu" de seu olhar, na perspectiva dessa tradição, irão perceber que a ação egoísta prejudica tanto o próximo como a si mesmo. Nota-se aqui que esse desconhecimento da verdade possui uma clara conotação moral, tendo em vista que o véu de Māyaa explica em certa medida a origem das ações egoístas, pois os indivíduos agem com base na ilusão da existência de um eu apartado da unidade de toda a realidade. No segundo capítulo desse trabalho, veremos que Schopenhauer, ao tratar das ações egoístas (que

\footnotetext{
${ }_{4}$ O compilador de Filosofias da Índia, Joseph Campbell, em nota, descreve que Māyā, da raiz mā, "medir, formar, construir", denota, em primeiro lugar, o poder de um deus ou demônio em produzir efeitos ilusórios, mudar de forma e parecer sob máscaras enganosas. Deriva daí o sentido de "magia", a produção de ilusões por meio sobrenaturais ou, simplesmente, "o ato de produzir ilusões" (...). Màyā, na filosofia vedantina, é especificamente "a ilusão sobreposta à realidade como efeito da ignorância"; (...) Sankara descreve todo o universo visível como sendo māyā, uma ilusão sobreposta à realidade pelos enganosos sentidos e pela mente não iluminada do homem. Cf. ZIMMER, Heinrich. Filosofias da Índia. Tradução de Nilton Almeida Silva, Cláudia Giovani Bozza e participação de Adriana Facchini de Césare. São Paulo: Palas Athena, 2012, p. 48.
} 
para ele são antimorais), relaciona esse tipo de ação com uma incapacidade de desprendimento das fantasmagorias (representações submetidas ao princípio de razão suficiente) que se apresentam à consciência humana, o que nos mostra que, mesmo com nomenclaturas distintas, a proposta schopenhaueriana propõe uma explicação que se assemelha à concepção de mundo presente na sabedoria milenar dos hindus.

Conforme estas considerações, podemos notar que as características de criação e ilusão são os aspectos primordiais de Māyā, os quais se revelam por meio da transitoriedade da vida. Este caráter ilusório de Māyā confunde a percepção do ser humano com relação ao próprio corpo, o que faz com que ele perca a identificação com seu "Eu" verdadeiro. Deste modo, podemos entender que a única maneira do indivíduo retirar este "véu" ilusório de seu olhar é buscando identificar o Absoluto dentro de si mesmo (Atman), em outros termos, buscar no irreal identificar o real.

De acordo com o não-dualismo transcendental da tradição védica, a partir da oposição entre a criação fenomênica de Mãyā e o Eu interior (Ätman) presente em todos os seres, os brâmanes reconhecem o significado do transcendente oculto na natureza. Tal reconhecimento podemos encontrar nos textos de revelação das Upanixades, mais especificamente pela "grande fórmula" védica (Mahāvākeyas ) Tat tvam asi (Isto és tu), descrita pelo diálogo apresentado na Chandogya Upanishad, o qual relata a instrução de um sábio brâmane a seu filho acerca da unidade imutável em todas as coisas da natureza.

Tal ensinamento revela, por analogia, que o princípio supremo ultrapassa a barreira dos nomes, ou seja, embora um objeto material possa assumir várias formas, seu ingrediente essencial estará sempre presente como o substrato de sua existência. Brabman é tão sutil como o germe da semente que está no fruto. Ele está presente em todos os seres transformando-se do invisível para o visível, convertendo-se em nomes e formas. Podemos considerar que as palavras do sábio chamam a atenção para que o indivíduo transcenda as aparências meramente fenomênicas proporcionadas por Màya e torne-se uno com a essência sutil presente em todos os seres da natureza, a qual está para além de um simples conhecimento.

Esta ideia é trabalhada na teoria ética de Schopenhauer, pois na ação genuinamente moral o indivíduo desprende-se do princípio de razão suficiente estabelecendo uma união com a natureza. Portanto, conforme estas considerações, podemos entender que essa fórmula resume o que há de fundamental como conhecimento para o indivíduo. Uma vez de posse desta

\footnotetext{
${ }^{5}$ Através da dissertação de mestrado de Mesquita. podemos confirmar que Mahāvākyas são quatro importantes ensinamentos das Upanishad, compondo as quatro grandes verdades do hinduísmo. A primeira grande Mahäväkya é "a consciência de Brabman" (Aitareya Upanisad); a segunda é "o ser ätman é Brabman" (Mändukya Upanisad); a terceira é "tat tvam asi” (Chändogya Upanisad); a quarta e última é "eu sou Brabman" (Brhadäranyaka Upanisad). Cf. MESQUITA. Fábio. Schopenhauer e o Oriente. 2007. 159 f. Dissertação (Mestrado) - Faculdade de Filosofia, Letras e Ciências Humanas da Universidade de São Paulo, São Paulo, 2007. p. 73.
} 
consciência universal de unidade, o sujeito terá discernimento suficiente para saber que, por exemplo, uma ação egoísta, na verdade, é apenas uma ilusão proporcionada por Māyā e que por meio da consciência, mediante a identificação da mais íntima essência com a substância suprema e invisível presente em tudo e em todos, conforme estabelecido na fórmula Tat tvam asi, o indivíduo combaterá essa ação enganadora e ultrapassará as formas das aparências fenomênicas criadas por Māyā, assim podendo alcançar o conhecimento da unidade imutável, do Real.

Em certa medida, Schopenhauer, se apropria tanto da concepção de ilusão (Māyāa), em sua teoria do mundo como representação, como do significado desta fórmula védica Tat tvam asi para melhor esclarecer o fundamento da ação moral em sua teoria ética.

\section{A fundamentação moral schopenhaueriana: a compaixão}

A compaixão surge no contexto filosófico de Schopenhauer, assumindo o caráter de uma potência libertadora do sofrimento humano. Para entendermos melhor esta questão, Schopenhauer nos apresenta em sua filosofia que o mundo é dado sob dois modos distintos, mas inseparáveis, a saber: o da Representação, que nos revela a pluralidade dos fenômenos, isto é, o lado do mundo que está imediatamente presente ao sujeito do conhecimento quando abre os olhos e reconhece todos os objetos existentes que lhe são dados a partir do tempo e do espaço; e por outro lado, o da Vontade, um pulso cego e irracional que, em si, está para além das aparências a que está limitado o nosso conhecimento, ou ainda "é a única coisa que o mundo revela para além da representação, ou seja, como a coisa-em-si" (SCHOPENHAUER, 2005, p. 235). Para que possamos compreender a teoria ética schopenhaueriana é necessário que entendamos previamente os conceitos de Representação e Vontade apresentados pelo autor em sua principal obra. Entretanto, aqui não discutiremos detalhadamente tais conceitos.

Compaixão (Mitleid) é uma palavra que, numa tradução literal, possui como significado “sofrer-com". Para Schopenhauer, tal sentimento é o fundamento que sustenta toda e qualquer ação genuinamente moral. Vale lembrar, porém, que a experiência compassiva, na perspectiva schopenhaueriana, transcende essa definição usual que mencionamos acima, haja vista que ela é acima de tudo uma experiência metafísica, a qual possibilita que o agente moral tenha uma compreensão intuitiva e imediata do mundo na figura do ser que sofre, fundida no seu próprio ser. Epistemologicamente, a relação entre sujeito e objeto, eu e mundo e eu e outro são completamente diluídas no momento do ato justo ou caridoso (virtudes morais schopenhauerianas). Isso se dá exatamente pelo fato de o sujeito conseguir momentaneamente 
"retirar o véu de Māya ${ }^{-6 "}$ da sua limitada percepção em face do sentimento de alteridade para com o outro nas experiências da genuína compaixão. Lembrando que essa experiência metafísica que o sujeito possui do mundo dá-se por meio da negação da vontade, do egoísmo, do "eu".

Os seres que conseguem enxergar o mundo para além do princípio de razão, não vendo mais fenômenos que agem mediante as motivações particulares que apareceram a partir das circunstâncias imediatas (base da ação egoísta), reconhecem que a essência íntima do mundo, a Vontade, da qual eles, como fenômenos, participam, é a fonte originária de todo sofrimento e dor sentida por cada ser que habita o mundo. Quando conseguimos contemplar o mundo a partir das Ideias, desprendendo-nos assim do nosso querer interior, não por interesse em conseguir algo para nós mesmos, mas para não mais promovermos desconsolação e carência no mundo, negando a vontade de outro, podemos afirmar que o homem agiu por amor puro ou compaixão:

A quem, portanto, atingiu essa última forma de conhecimento, a esse tornar-se-á claro que, como Vontade é o em-si do fenômeno, o tormento infligido a outrem, o tormento experimentado por si mesmo, o mal, o padecimento concernem sempre e exclusivamente a uma única e mesma essência, embora os fenômenos nos quais se expõe existam como indivíduos inteiramente diferentes e até mesmo separados por completo de e espaço. Verá que a diferença entre que inflige sofrimento e quem tem de suportá-lo é apenas fenômeno e não atinge a coisa-em-si, isto é, a Vontade que vive em ambos. Vontade que, aqui, enganada pelo conhecimento atado ao seu serviço, desconhece a si, procurando em UM de seus fenômenos o bem-estar, porém em OUTRO produzindo grande sofrimento, e, desta forma, em ímpeto veemente, cava dos dentes na própria carne sem saber que fere sempre a si própria, manifestando-se desse modo médium da individuação e o conflito dela consigo mesma, // que porta em seu próprio interior. O atormentador e atormentado são unos. (SCHOPENHAUER, 2005, p. 452)

O conhecimento submetido ao princípio de razão não permite que o indivíduo reconheça que a Natureza inteira, na luta interna cotidiana e interminável travada até mesmo entre os seres de uma mesma espécie, a fim de preservar o seu ímpeto de vontade de Vida, só sucumbe como fenômeno, nunca como Vontade mesma. Nascimento e morte aplicam-se tão somente aos fenômenos, de modo algum à Vontade.

Esse conhecimento do mundo desprendido do princípio de razão faz com que seja possível reconhecer o sofrimento alheio como nosso, não mensurando a desconsolação e a dor do outro como menor ou inferior à nossa, pois os nossos interesses não são o alvo da nossa ação, mas o desconsolo e a carência do outro. Quando o direcionamento do agir nega a nossa própria

\footnotetext{
${ }^{6}$ Moreira problematiza a retirada do véu de Mãyā no tocante à experiência moral do seguinte modo: "Mas, e na problemática ética, o que impulsiona o sujeito na direção da dissolução do Véu de Maia? A resposta é simples: O sujeito nega sua individualidade e ultrapassa o Véu de Maia ou a partir do conhecimento intuitivo do sofrimento inerente à vida, ou através do sofrimento imediato, diretamente sentido. Será o sofrimento, a falta, o desamparo, que despertará em nós o sentimento de filiação ao outro. Só na dor nos compadecemos uns dos outros”. Cf. MOREIRA, Jacqueline. O problema da fundamentação da ética na filosofia de Schopenhauer. Educação e Filosofia, Uberlândia, v. 20, n. 40, p. 207-241, jul./dez. 2006.
} 
vontade, deixamos de sobrepujar o nosso querer face ao querer de outrem, evitando o sofrimento do mundo. Quando o conhecimento intuitivo do mundo entra em ação, o sujeito reconhece que ele não é apenas alvo de sofrimento, mas causador do sofrimento alheio:

\begin{abstract}
Nesse sentido, não importa o que é a bondade, o amor e a nobreza de caráter possam fazer pelos outros, tem-se aí sempre apenas o alívio dos sofrimentos; conseguintemente o que pode mover a bons atos, a obras de amor é sempre e tão-somente o CONHECIMENTO DO SOFRIMENTO ALHEIO, compreensível imediatamente a partir do próprio sofrimento e posto no mesmo patamar deste. Daí, no entanto, seguese o seguinte: o amor puro (caritas), em conformidade com a sua natureza, é compaixão, e o sofrimento que alivia, ao qual pertence todo desejo insatisfeito, tanto pode ser grande quanto pequeno. (SCHOPENHAUER, 2005, p. 477)
\end{abstract}

Diante do exposto, podemos afirmar que, quando a vontade é negada a partir desse conhecimento íntimo que temos do mundo, o que sentimos interiormente não é sofrimento, dor, tédio, insatisfação, decorrentes de uma impossibilidade de insatisfação do querer, mas bem-estar e alívio mediante a ação compassiva desprendida de motivações particulares. Seguindo a linha de pensamento schopenhaueriana, podemos caracterizar tais ações desinteressadas como as únicas ações genuinamente morais. Em contrapartida, as ações que são movidas por interesses e que levam em consideração apenas o seu querer face aos motivos que apareceram, portanto egoístas, não podem ser consideradas morais.

Schopenhauer destacou um simples moralizar $^{7}$ como uma ação voltada apenas para si mesma, ou seja, movida pelo amor próprio, portanto egoísta. Tal ação não possui nenhum valor moral, pois fornece apenas motivos para agir, e estes podem até mudar a direção da vontade, porém não a influenciam. Em outros termos, o autor esclarece que o conhecimento abstrato, por mais que guie a vontade, não é capaz de modificar aquilo que verdadeiramente o homem quer, permanece o mesmo. Assim, Schopenhauer estabelece que, apenas por meio do conhecimento intuitivo, podemos encontrar um fundamento válido para a ação moral, pois somente ele permite ao indivíduo reconhecer no outro a sua própria essência.

Assim, Schopenhauer estabelece sua metafísica da Vontade, a qual tem sua fonte voltada para a experiência interior que cada indivíduo possui de seu próprio corpo em ação, decretando, deste modo, uma metafísica imanente. Por conseguinte, o autor nos ensinou que a busca do verdadeiro fundamento moral deve ser feita por meio da experiência, isto é, pela observação da vida dos seres humanos e de suas atitudes, pois somente assim será revelada a existência da compaixão, que é capaz de deter os fortes impulsos do egoísmo, pois ela se ocupa das ações desinteressadas, não exige tanta reflexão. Trata-se de um conhecimento intuitivo, por isso pode ser encontrada em qualquer indivíduo desde o menor até o mais intelectual dos homens.

\footnotetext{
${ }^{7}$ Cf. SCHOPENHAUER, 2005, p 468
} 
Em conformidade a estas considerações surge a questão da motivação da ação. O que se deve levar em conta no momento da ação ou ainda como o outro pode ser inteiramente a única motivação do meu modo de agir? Segundo Schopenhauer, a única solução seria somente por meio do fato de que o outro se torne o fim último de minha vontade, como eu próprio o sou ${ }^{8}$. Ou seja, minha ação deve querer imediatamente o bem do outro, como se fosse o meu próprio. Isto exige que eu me identifique com o outro e que as diferenças proporcionadas pelo egoísmo sejam suprimidas. Segundo Schopenhauer, esse processo é real e menos raro do que podemos imaginar, pois se trata do "fenômeno diário da compaixão". Ele enfatiza que é a participação imediata no sofrimento de outra pessoa o critério que nos permite classificar uma ação moralmente válida, pois, para ele, só aquela que procede efetivamente da compaixão atinge esse patamar.

Uma ética assim destaca-se pela nobreza e dignidade da ação humana, pois ela acontece de maneira misteriosa ${ }^{9}$ no cotidiano da vida, mediante nossas experiências com o próximo. Portanto, segundo a teoria ética schopenhaueriana, o processo da compaixão é o único capaz de promover e explicar as atitudes desinteressadas de um homem em relação a outro. Nas considerações éticas de Schopenhauer a compaixão não se restringe somente ao homem, mas sim a todos os seres vivos. Neste sentido, o filósofo revelou indignação por aqueles que maltratam os animais, afirmando que estes são irresponsavelmente malcuidados nos outros sistemas morais europeus.

Conforme a esses esclarecimentos, podemos afirmar que a teoria ética de Schopenhauer não nasce de um dever, mas em função de uma experiência imediata de identificação com o outro, a qual, conforme o filósofo, é metafísica, isto é, consiste no fato de um indivíduo reconhecer a si próprio, sua verdadeira essência, imediatamente no outro. Tais considerações nos revelam um fundamento ético estabelecido por meio da ação compassiva o qual se opõe à maldade e ao egoísmo, permitindo-nos atingir um grau de consciência do verdadeiro sentido do que é ser humano. Ainda nessas considerações, o autor nos apresenta um novo ser ético, o qual é conduzido à ação moral pelo sentimento de compaixão decorrente do conhecimento intuitivo e imediato. Por meio de tal conhecimento somos capazes de identificar uma unidade presente em todos os seres, de modo que esta experiência nos conduz a uma ação moral, pois o sujeito que conhece age com verdadeiro valor moral, sabendo que a dor do outro também é sua e que sofre junto com ele.

Tendo em vista a questão central discutida neste trabalho, ou seja, sobre a influência do pensamento oriental na teoria ética de Schopenhauer, consideramos que:

${ }^{8}$ Cf. SCHOPENHAUER, 2001, pp. 134-135

${ }^{9}$ Cf. SCHOPENHAUER, 2001, p. 136 
A contribuição da sabedoria oriental presente na teoria ética schopenhaueriana apresenta-se justamente pela identificação de um elemento comum presente em ambos os pensamentos, a saber, a consciência de uma essência íntima presente em todos os seres vivos que dá unidade a toda realidade existente. Nas Upanixades tal ideia é comunicada pela fórmula védica Tat tvam asi, a qual revela que tudo é um, ou seja, que existe uma unidade essencial presente em todos os seres e que somente esta essência é considerada pela tradição como a verdadeira realidade, de maneira que todo o lado empírico do mundo é ilusão (Māya). Na filosofia de Schopenhauer essa ideia é expressa pela identidade una da Vontade que está em toda natureza, de modo que, na ação mora, essa essência apresenta-se à consciência do sujeito e este, por sua vez, reconhece-a imediatamente no outro, identificando que as dores e padecimentos daquele também são suas. Tal experiência é resultante da ação compassiva, a qual, portanto, constitui a genuína ação moral schopenhaueriana.

Outro fator que contribui para nossa consideração acerca da influência do pensamento oriental na teoria ética de Schopenhauer pode ser enfatizado pelo fato desse filósofo ocidental destacar que as práticas vivenciadas pela ética dos hindus baseiam-se na essência da humanidade. Essa declaração revela que, ao contrário das éticas ocidentais, nosso autor admira e concorda com os preceitos éticos hindus. Unindo os dois pensamentos, podemos afirmar que, aquele indivíduo que pratica obras de amor possibilita que o véu de Màyā se torne transparente, de modo que a ilusão do princípio de individuação o abandona. Portanto, conforme Schopenhauer nos esclarece, superar a ilusão de Māyā e praticar obras de amor são uma única e mesma coisa. Por conseguinte, com base nestas considerações, podemos afirmar que existe uma contribuição significativa dos ensinamentos da sabedoria oriental na filosofia de Schopenhauer e, mais propriamente, em sua teoria ética.

\section{REFERÊNCIAS BIBLIOGRÁFICAS}




\section{OBRAS DE SCHOPENHAUER:}

SCHOPENHAUER, Arthur. Aforismos para a sabedoria de vida. São Paulo: Martins Fontes, 2001.

. A arte de escrever. Organização, tradução, prefácio e notas de Pedro Süssekind. Porto Alegre: L\&PM, 2005.

A metafísica do belo. Tradução, apresentação e notas de Jair Barboza. São Paulo: UNESP, 2003.

De la quadruple racine du príncipe de raison suffisante. Tradução de FrançoisXavier Chenet. Paris: Librairie Philosophique J. Vrin, 1997.

E1 mundo como vonluntad y representacion II. Tradução de Eduardo Ovejero y Maury. Buenos Aires: Losada, 2008.

Fragmentos para a história da filosofia. Tradução, apresentação e notas de Maria Lúcia Cacciola. São Paulo: Iluminuras, 2003.

Edizioni, 2007.

Il mio Oriente. Tradução e apresentação de Giovanni Gurisatti. Milão: Adelphi

. Metafísica do amor, Metafísica da morte. São Paulo: Martins Fontes, 2004.

O mundo como vontade e representação. Tradução, apresentação e notas de Jair Barboza. São Paulo: UNESP, 2005.

. Sobre o fundamento da moral. Tradução de Maria Lúcia Cacciola. São Paulo: Martins Fontes, 2001.

Parerga y Paralipómena I. Tradução e notas de Pilar Lúpes de Santa María. Madrid: Editorial Trotta, 2009.

Parerga y Paralipómena II. Tradução e notas de Pilar Lúpes de Santa María. Madrid: Editorial trotta, 2009.

\section{OUTRAS OBRAS:}

APP, Urs. Notes and excerpts by Schopenhauer Related to Volumes 1-9 of the Asiatic Researches. Schopenhauer Jahrbuch, Frankfurt, v. 79, pp. 11-33. 1998.

Schopenhauer's Initial Encounter with Indian Thought. Schopenhauer Jahrbuch, Frankfurt, v. 87, pp. 35-76. 2006.

BARBOZA, Jair. Schopenhauer: a decifração do enigma do mundo. São Paulo, 1997.

BARBOZA, Jair. Schopenhauer: Die Erscheinung, das Phänomen. Voluntas: Estudos sobre Schopenhauer, São Paulo, v. 5, n. 1, pp. 03-08, jan./jun. 2014. 
Schopenhauer. São Paulo: Editora Moderna, 1997.

BERGER, Douglas. The veil of Mãyã: Schopenhauer's system and early Indian thought. New York: Global Academic Publishing Binghamton, 2004.

BITTENCOURT, Renato. Justiça, caridade e compaixão na Metafísica da Ética de Schopenhauer. Voluntas: Estudos sobre Schopenhauer, São Paulo, v. 1, n. 1, pp. 49-70, jan./jun. 2010.

BORREL, Roviralta. Bhagavad-Gitâ. Tradução de Eloísa Ferreira. São Paulo: Editora Três, 1973.

CACCIOLA, Maria Lúcia. Schopenhauer e a Questão do Dogmatismo. São Paulo: Edusp, 1994.

DEBONA, Wilmar. Schopenhauer e as formas da rąão: o teórico, o prático e o ético-místico. São Paulo: Annablume, 2010

GRIFFITHS, Bede. Rio de compaixão: um comentário cristão ao Bhagavad Gita. Tradução de Roldano Giuntoli. São Paulo: Ed. É Realizações, 2011.

ISHERWOOD, Christoph. Introdução ao Vedanta. Tradução de Myriam Facchini Chohfi. São Paulo: Editora Pensamento, 1987.

JANAWAY, Christopher. Schopenhauer. São Paulo: Edições Loyola, 1994. (Coleção Mestres do Pensar)

KANT, Immanuel. Crítica da Razão Prática. Lisboa: Edições 70, 1986. (Coleção Textos Filosóficos).

MAGEE, Bryan. História da Filosofia. Tradução de Marcos Bagno. São Paulo: Edições Loyola, 1999.

MANN, Thomas, O Pensamento vivo de Schopenhauer. São Paulo: Editora Martins, 1975. (Coleção Biblioteca do Pensamento Vivo).

MESQUITA. Fábio. Schopenhauer e o Oriente. 2007. 159 f. Dissertação (Mestrado) - Faculdade de Filosofia, Letras e Ciências Humanas da Universidade de São Paulo, São Paulo, 2007.

MOREIRA, Jacqueline. O problema da fundamentação da ética na filosofia de Schopenhauer. Educação e Filosofia, Uberlândia, v. 20, n. 40, p. 207-241, jul./dez. 2006.

NICHOLLS, Moira. The Influences of Eastern Thought on Schopenhauer's Doctrine of the Thing-in-Itself. In: JANAWAY, Christopher (Org.). The Cambridge companion to Schopenhauer. Cambrigde: Cambridge University Press, 1999, pp. 171-212.

PERNIN, Marie José. Schopenhauer: Decifrando o Enigma do Mundo. Tradução de Lucy Magalhães. Rio de Janeiro: Jorge Zahar, 1995. 
PRABHAVANANDA, Swami. Os Upanishads: Sopro vital do eterno. São Paulo: Pensamento, 1980.

PRABHUPADA, Abhay; BHAKTIVEDANTA Swami. Srimad-Bhãgavatam. Tradução e significados elaborados pelos discípulos de A.C. Bhaktivedanta Swami e Prabhupada. São Paulo: The Bhaktivedanta Book Trust, 1995.

REDYSON, Deyve. Schopenhauer e o pensamento e o pensamento oriental: entre o hinduísmo e o budismo. Religare, João Pessoa, v. 7, n. 1, pp. 3-16, mar. 2010.

SAFATLE, Vladimir. Grande hotel abismo. Por uma reconstrução da teoria do reconhecimento. São Paulo: Martins Fontes, 2012.

SAFRANSKI, Rudiger. Schopenhauer e os anos mais selvagens da filosofia. Tradução de William Lagos. São Paulo: Geração Editorial, 2011.

STAUDT, Leo. Decifração do enigma moral em Schopenhauer e Tugendhat. Ethic@, Florianópolis, v.3, n. 2, p.163-176, dez. 2004.

TINÔCO, Carlos Alberto. As Upanishads. São Paulo: IBRASA, 1996.

ZIMMER, Heinrich. Filosofias da Índia. Tradução de Nilton Almeida Silva, Cláudia Giovani Bozza e participação de Adriana Facchini de Césare. São Paulo: Palas Athena, 2012. 